\title{
Review Article \\ Food Processing and Maillard Reaction Products: Effect on Human Health and Nutrition
}

\author{
Nahid Tamanna ${ }^{1}$ and Niaz Mahmood ${ }^{2}$ \\ ${ }^{1}$ Graduate Program in Biological Sciences, University of Manitoba, Winnipeg, MB, Canada R3T 2N2 \\ ${ }^{2}$ Graduate Program in Biochemistry and Medical Genetics, University of Manitoba, Winnipeg, MB, Canada R3E 0J9 \\ Correspondence should be addressed to Nahid Tamanna; nt.mitul@gmail.com
}

Received 28 July 2014; Revised 18 December 2014; Accepted 24 December 2014

Academic Editor: Mitsuru Yoshida

Copyright ( 2015 N. Tamanna and N. Mahmood. This is an open access article distributed under the Creative Commons Attribution License, which permits unrestricted use, distribution, and reproduction in any medium, provided the original work is properly cited.

\begin{abstract}
Maillard reaction produces flavour and aroma during cooking process; and it is used almost everywhere from the baking industry to our day to day life to make food tasty. It is often called nonenzymatic browning reaction since it takes place in the absence of enzyme. When foods are being processed or cooked at high temperature, chemical reaction between amino acids and reducing sugars leads to the formation of Maillard reaction products (MRPs). Depending on the way the food is being processed, both beneficial and toxic MRPs can be produced. Therefore, there is a need to understand the different types of MRPs and their positive or negative health effects. In this review we have summarized how food processing effects MRP formation in some of the very common foods.
\end{abstract}

\section{Introduction}

The Maillard reaction has been named after the French physicist and chemist Louis Camille Maillard (1878-1936) who initially described it. It is often defined as nonenzymatic browning reaction. While foods are processed or cooked at high temperature, a chemical reaction occurs between amino acids and reducing sugars which generate different flavours and brown colour (Figure 1). So it is often used in food industry for giving food different taste, colour, and aroma.

Based on literature, Hodge (1953) first described the steps involved in Maillard reaction products (MRPs), also known as advanced glycation end-products (AGEs), formation. The whole process of MRPs formation can be divided into three major stages depending on colour formation. At the first stage, sugars and amino acid condense, and following condensation, Amadori rearrangement and 1-amino-1deoxy2 ketose form. In the second stage, dehydration and fragmentation occur in the sugar molecules. Amino acids are also degraded in this stage. Hydroxymethylfurfural (HMF) fission products such as pyruvaldehyde and diacetyl are formed in this intermediate stage. This stage can be slight yellow or colourless. In the final stage, aldol condensation occurs and finally the heterocyclic nitrogenous compounds form, melanoidins, which is highly coloured [1]. Maillard reaction can also take place in living organisms. It has been reported that some MRPs particularly melanoidins have beneficial effects on health such as antioxidative [2] and antibiotic [3] effects. However some reports have also suggested that MRPs such as high carboxymethyl lysine (CML) promote diabetes and cardiovascular diseases while acrylamide acts as a carcinogen [4-6].

There is an ever-increasing preference for instant meal rather than traditional cooking, especially among the new generation of people. It has been reported that people consuming high amount of processed meat, pizza, or snacks develop insulin resistance and metabolic syndrome compared to people having high intake of vegetables and low processed food [7]. MRPs that change during food processing might be one of the important factors for either disease progression or combating diseases. In this review, we have summarized the changes of MRPs which occur during processing of foods. 


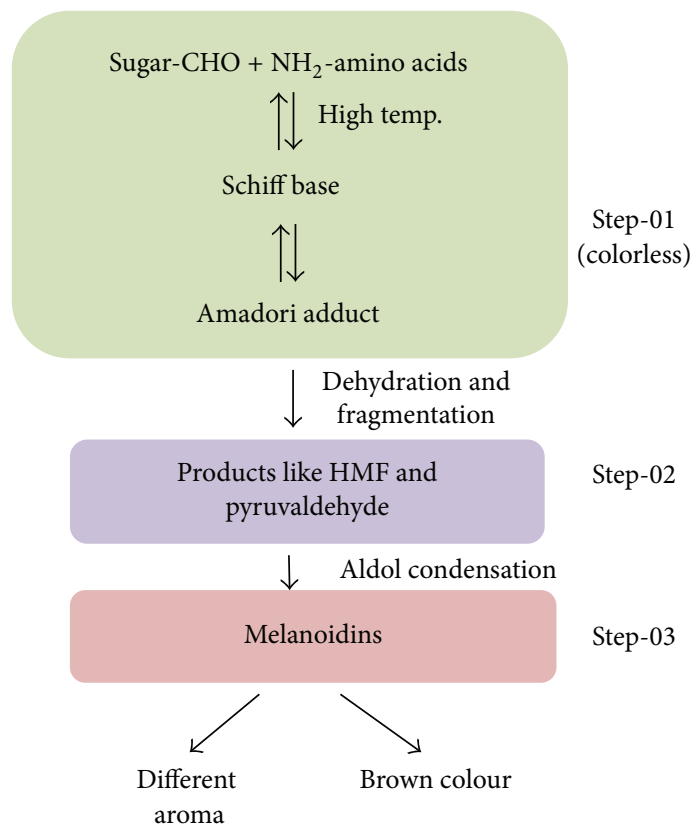

FIGURE 1: Schematic representation of "Maillard reaction" and flavour formation in food.

\section{Soybean Processing and MRPs Formation}

Soybean is widely used as flours, grits, flakes, isolates, concentrates, and textured soya proteins and also as cooking oil. Soybeans play important role in cardiovascular diseases, osteoporosis, and cancer [8]. So processing of soybean is an important factor for maintaining its nutritional quality. Cooking at high temperature may generate MRPs which can be good or bad for health. However, soybean must be processed before consumption. Žilić et al. (2014) assessed the level of furosine, hydroxymethylfurfural (HMF), and acrylamide in soybean during extrusion, microwave, and infrared heating processes [9]. They found that microwave heating for short time (1-2 min) generates high levels of acrylamide, whereas long time heating (3-5 min) generates lower levels of acrylamide. During extrusion and infrared heating, acrylamide formation greatly increased with time and temperature. HMF level increased in all three processes with increased time and temperature and it was significantly higher in microwave treatment. From the beginning of heat treatment, furosine level was higher in the extrusion and infrared treatment whereas in the microwave heating it was increased to maximum value after $3 \mathrm{~min}$ but at $4 \mathrm{~min}$ this value was similar with $2 \mathrm{~min}$. Their results showed that microwave heating improved the antioxidant properties of soybean by $50 \%$ compared to raw soybean [9]. Even though this study has reported that total flavonoids increase at $100^{\circ} \mathrm{C}$ with the exception of microwave heating which occurs at $45^{\circ} \mathrm{C}$, another study showed that when soybean is soaked in water and heated afterwards at $98^{\circ} \mathrm{C}$, almost half (44\%) of the raw flavonoids were lost in the final product [10]. This might be due to the presence of moisture content since decreasing moisture was shown to be associated with elevated levels of MRPs in the extrusion and infrared heat treatment [9].

\section{MRPs on Milk Processing}

Milk is a beverage that is consumed throughout the world. At present, a large percentage of the milk consumed by people, especially in the western countries, is processed rather than raw milk. Ultra high temperature (UHT) treatment or conventional sterilization process is often used to process milk for improving quality and safety. Milk is rich in protein and sugar. So it is obvious that processing of milk at high temperature may lead to the formation of MRPs. Several methods have been approached to determine the extent of MRPs during milk processing. Both initial and advanced staged MRPs have been used as indicators of browning reaction which occurred in milk $[11,12]$. MRP formation affects protein and mineral bioavailability greatly. In the early stages, lactose in milk blocks the amino group of lysine to form the Amadori product called lactulosyllysine which changes the protein bioavailability [13]. It is also known that MRPs may behave as chelating agents to chelate metal cations by forming different soluble and insoluble complexes and thereby can affect mineral bioavailability [14]. So processing of milk by heat-treatment requires attention, especially for the infants, as milk is the sole source of nutrients at that stage of life.

It has been reported that conventional sterilized bottle milk has different chemical composition compared to the UHT treated milk [15]. HMF level is often used to assess the progression of MRPs formation. However, milk processed at UHT may have different levels of HMF [16] due to the presence of some other factors such as vitamin A, casein, and iron [17]. So during milk processing, along with heat treatment, other relevant factors should be considered for preserving the nutritious value. A recent study has shown that use of enzymes like Faox I and Faox II might inhibit Maillard reaction development [18].

\section{Pasta Processing and MRPs}

Pasta is considered one of the healthy foods suited to balanced diet; and its consumption is becoming increasingly high throughout the world. Pasta has different varieties and shapes. Till 2009, 310 different types of both dried and fresh pasta have been documented [19]. Although an Italian law exists for making high quality pasta [20], different steps of pasta processing cycle such as mixing, kneading, shaping, and drying can affect the pasta quality. Among these four steps, drying is most important for the quality of the product. For traditional drying methods, low temperatures $\left(29\right.$ to $40^{\circ} \mathrm{C}$ ) are required but it takes 24 to 60 hours to complete the process. So for time management and to increase the production rate, high-temperature short-time drying processes have been widely preferred. While pasta is processed at high temperature, it brings benefits in terms of productivity, cost, colour intensity, and nutritious value [21]. Moreover, application of high drying temperatures in pasta increases firmness 
and decreases stickiness [22]. Besides these beneficial effects, high heat treatment leads to the formation of MRPs that ultimately can change flavor, color, functional properties, and nutritional value [23]. Furosine is widely used as pasta quality assessment. It has been reported that pasta processed at high temperature had decreased level of total carotenoid level [24]. Along with furosine, maltulose is also proposed as a maker for pasta quality assessment [25].

\section{Meat Processing and MRPs}

MRPs like heterocyclic amine (HCA) level increases with elevated cooking temperature; and this phenomenon is more pronounced in meat than fish [26]. Meat is cooked at high temperature either by frying, roasting, and boiling or in oven. While positive correlations have been found between the intakes of HCAs from foods and increased risk of various types of human cancer [27-29], some other studies have not found any correlation between HCAs and cancer risk [30-32]. Several studies have demonstrated that processes like frying and broiling can cause the formation of high amounts of HCAs [27, 33-35]. On contrary, these HCAs produce different flavour and tastes in foods. Heterocyclic compounds such as pyrazine, oxazole, and thiazoles are primarily responsible for forming flavour in roasted compound. During high heat treatment and grilling process, pyrazines level significantly increased [36]. It is suggested that the alkylpyrizne is formed via the condensation of two alpha amino ketone molecules derived from the Strecker degradation [37], which is an intermediate of Maillard reaction pathway.

In processed food, more than 25 types of heterocyclic amines (HCA) have been identified [38]. A study has shown that when duck meat was cooked by charcoal grilling, deepfrying, roasting, microwave cooking, pan frying, or boiling, MRPs were higher in the pan frying process compared to the other four methods of cooking. Liao et al. (2012) [39] reported that boiling and microwave cooking were the most appropriate methods to process duck meat in terms of MRPs formation. However in another study, it has been found that both charcoal grilled duck and chicken breast had high level of HCAs compared to pan fried meat. They found that roasting decreases HCAs significantly [40].

In another study, beef steak and hamburger patties were processed by pan-frying, oven-broiled, and grilled or barbecued to four levels of doneness (rare, medium, well cooked, or very well cooked) [41]. Beef roasts were processed on oven by rare, medium, and well cooking. They measured five different HCAs. The level of 2-amino-3,4-dimethylimidazo[4,5$f$ ] quinoline was higher in well-cooked steak and hamburger patties. Like duck and chicken roast, roasting beef did not contain any of the 5 HCAs, but the gravy made from the drippings from well-done roasts had two types of HCAs [41]. From the three different studies, it can be suggested that roasting of meat (chicken, duck, and beef) generates less amount of HCAs compared to other methods.

In recent days, people consume more ready-to-eat food due to lack of time. Puangsombat et al. (2011) assessed HCAs level in some ready-to-eat products. They found that
HCAs were higher in rotisserie chicken skin. In the other assessed food, HCA level was found in the order as follows: rotisserie chicken meat, deli meat products, and pepperoni [42]. However, it has been reported that commercially cooked meats and restaurant meats contain low amounts of HCAs $[43,44]$.

\section{Coffee Bean Processing and MRPs}

As a beverage, coffee is an important item in the lives of billions of people and is also one of the most traded food products in the world. The brewed coffee has emerged as the second most consumed drink after water $[45,46]$. The desirable fragrance of coffee beverages develops during roasting procedures. Typical roasting temperatures range from 180 to $250^{\circ} \mathrm{C}$, and roasting time varies between 2 and 25 min depending on the process employed [47]. During roasting procedures, internal temperature exceeds $180^{\circ} \mathrm{C}$ which results in the occurrence of Maillard reaction, carbohydrate caramelization, and pyrolysis of organic compounds [47]. Maillard reaction generates melanoidins upon roasting, which accounts for $29 \%$ of the dry weight of brewed coffee bean [47]. Coffee melanoidins are formed via polymerization reactions of furans and/or pyrroles, during the advanced stages of the Maillard reaction, and linked by poorly defined polycondensation reactions [48]. Even though roasting decreases coffee bean carbohydrates, protein, and lipid level, the level of caffeine remains relatively stable on roasting. MRPs, caffeine, nicotinic acid, and some other components of coffee bean protect teeth from Streptococcus mutans which is considered to be the major causative agent of dental caries in humans [49].

\section{Plant Derived Food Processing and MRPs}

Consumption of diets rich in fruits and vegetables renders many health benefits to us. However, processing method plays an important role in dictating the magnitude of the beneficial health effects obtained from fruits and vegetables. Depending on treatment temperature, furoylmethyl derivatives (FM) have been found in processed vegetables and fruits like orange juices [50] and processed tomato products [51] and also in dehydrated carrots [52]. It has been shown that dehydrated carrot contains significantly high amount of FM compared to carrot juices, baby carrot, or tinned carrot. It is suggested that processing time during the heat treatment plays an important role for FM formation [52]. Dueik and Bouchon (2011) have reported that, by vacuum frying of carrot chips, potato and apple slices can help to retain their total carotenoids and ascorbic acid levels significantly [53].

When vegetables are treated at low temperature, prooxidants are generated, whereas treating at high temperature decreases the prooxidants and increases antioxidant properties due to the production of MRPs [54]. Such antioxidant activity of the MRPs comes from the high molecular weight brown compounds that are formed in the advanced stages of the reaction [54]. However, it should be mentioned here that MRPs can also exhibit prooxidant properties $[55,56]$. 
MRPs can prevent the enzymatic browning reaction caused by polyphenol oxidase (PPO) [57]. Plant derived products, such as fruits and vegetables, produce many endogenous phenolic compounds during postharvest handling and processing. These compounds are oxidized by oxidoreductase enzymes like polyphenoloxidases (PPOs) and tyrosinases. This reaction, in turn, generates highly reactive quinonic compounds that are condensed and polymerized to produce brown pigments and thereby decreases the quality of the food product. MRPs can prevent this enzymatic process at the initial step of this reaction and thereby help to maintain the product quality. Besides antibrowning, MRPs has also been shown to render antiallergenic property for cherry derived allergens [58].

\section{Some Other Impacts of MRP-Derived Food}

Angiotensin-I converting enzyme (ACE) is the regulatory enzyme for upregulation of blood pressure. ACE inhibitory peptide lowers blood pressure by inhibiting ACE enzyme [59]. Rufián-Henares and Morales (2007) have demonstrated that the melanoidins isolated from seven amino acid-glucose model systems were all shown to cause inhibition of ACE in vitro [60]. Recently, Hong and colleagues (2014) have shown that, under the appropriate conditions, Maillard reaction can effectively improve the ACE inhibitory activity of casein hydrolysate [61].

It has been claimed that administration of a Maillard browning reaction product obtained from an extract of Panax species plant comprising ginsenoside $\mathrm{Re}$ or ginsenosidederived saccharide treated with amino acid at temperatures between 100 and $130^{\circ} \mathrm{C}$ can either prevent, improve, or treat a renal disease [62].

Food derived versatile MRPs can act as bactericidal for a wide number of pathogens. For example, aminoreductone can act as a more effective bactericidal for four Pseudomonas aeruginosa isolates, one multidrug-resistant Pseudomonas aeruginosa (MDRP), one Escherichia coli, one methicillin-susceptible Staphylococcus aureus, and one methicillin-resistant Staphylococcus aureus (MRSA) compared to mikacin, ciprofloxacin, imipenem, and levofloxacin [63]. MRPs have also been shown to be effective against yeast [64].

\section{Conclusion and Perspectives}

Maillard reaction products have both positive and negative impacts on health. Diverse MRPs act as antioxidants, bactericidal, antiallergenic, antibrowning, prooxidants, and carcinogens. Most of these properties depend on processing of food. High temperature heating makes some food nutritious, whereas some of the foods lose their nutritional value. Many strategies are employed in the food industries to reduce the production of MRPs. For example, acrylamide has been classified as a probable carcinogen to humans by the International Agency for Research on Cancer [65]. During food preparation at high temperature, acrylamides are formed in many types of foods via Maillard reaction [6668]. To reduce the amount of acrylamide, asparaginase has been successfully used in laboratory for potatoes and cereals $[69,70]$. It has also been reported that injection of $\mathrm{CO}_{2}$ during extrusion process helps to reduce the level of acrylamide [71].

This review was aimed at summarizing our current knowledge regarding the changes in food mediated by Maillard reaction during the food processing steps. This may provide useful insights for those related to food processing facilities.

\section{Conflict of Interests}

The authors declare that there is no conflict of interests regarding the publication of this paper.

\section{References}

[1] J. E. Hodge, "Dehydrated foods: chemistry of browning reactions in model systems," Journal of Agricultural and Food Chemistry, vol. 1, no. 15, pp. 928-943, 1953.

[2] F. Natella, M. Nardini, I. Giannetti, C. Dattilo, and C. Scaccini, "Coffee drinking influences plasma antioxidant capacity in humans," Journal of Agricultural and Food Chemistry, vol. 50, no. 21, pp. 6211-6216, 2002.

[3] S. Hiramoto, K. Itoh, S. Shizuuchi et al., "Melanoidin, a food protein-derived advanced Maillard reaction product, suppresses Helicobacter pylori in vitro and in vivo," Helicobacter, vol. 9, no. 5, pp. 429-435, 2004.

[4] J. Meng, N. Sakata, S. Takebayashi et al., "Glycoxidation in aortic collagen from STZ-induced diabetic rats and its relevance to vascula damage," Atherosclerosis, vol. 136, no. 2, pp. 355-365, 1998.

[5] E. Tareke, P. Rydberg, P. Karlsson, S. Eriksson, and M. Törnqvist, "Acrylamide: a cooking carcinogen?" Chemical Research in Toxicology, vol. 13, no. 6, pp. 517-522, 2000.

[6] K. J. Knecht, J. A. Dunn, K. F. McFarland et al., "Effect of diabetes and aging on carboxymethyllysine levels in human urine," Diabetes, vol. 40, no. 2, pp. 190-196, 1991.

[7] A. Esmaillzadeh, M. Kimiagar, Y. Mehrabi, L. Azadbakht, F. B. Hu, and W. C. Willett, "Dietary patterns, insulin resistance, and prevalence of the metabolic syndrome in women," The American Journal of Clinical Nutrition, vol. 85, no. 3, pp. 910918, 2007.

[8] M. Messina and V. Messina, "Soyfoods, soybean isoflavones, and bone health: a brief overview," Journal of Renal Nutrition, vol. 10, no. 2, pp. 63-68, 2000.

[9] S. Žilić, B. A. Mogol, G. Akillioğlu, A. Serpen, N. Delić, and V. Gökmen, "Effects of extrusion, infrared and microwave processing on Maillard reaction products and phenolic compounds in soybean," Journal of the Science of Food and Agriculture, vol. 94, no. 1, pp. 45-51, 2014.

[10] C.-J. C. Jackson, J. P. Dini, C. Lavandier et al., "Effects of processing on the content and composition of isoflavones during manufacturing of soy beverage and tofu," Process Biochemistry, vol. 37, no. 10, pp. 1117-1123, 2002.

[11] F. Evangelisti, C. Calcagno, and P. Zunin, "Relationship between blocked lysine and carbohydrate composition of infant formulas," Journal of Food Science, vol. 59, no. 2, pp. 335-337, 1994.

[12] L. Pizzoferrato, P. Manzi, V. Vivanti, I. Nicoletti, C. Corradini, and E. Cogliandro, "Maillard reaction in milk-based foods: 
nutritional consequences," Journal of Food Protection, vol. 61, no. 2, pp. 235-239, 1998.

[13] H. Erbersdobler, Twenty Years of Furosine-Better Knowledge about the Biological Significance of Maillard Reaction in Food and Nutrition, Elsevier Science, Amsterdam, The Netherlands, 1986.

[14] M. Friedman, "Food browning and its prevention: an overview," Journal of Agricultural and Food Chemistry, vol. 44, no. 3, pp. 631-653, 1996.

[15] A. Olano, M. M. Calvo, and N. Corzo, "Changes in the carbohydrate fraction of milk during heating processes," Food Chemistry, vol. 31, no. 4, pp. 259-265, 1989.

[16] S. Albalá-Hurtado, M. T. Veciana-Nogués, A. Mariné-Font, and M. C. Vidal-Carou, "Progress of browning reactions during storage of liquid infant milks," Journal of Agricultural and Food Chemistry, vol. 47, no. 10, pp. 4033-4037, 1999.

[17] Y. Park and Y. Hong, "Comparison of the heat treatment intensity in infant formulae," Korean Journal of Food Science and Technology, vol. 23, 1991.

[18] A. D. Troise, N. A. Dathan, A. Fiore et al., "Faox enzymes inhibited Maillard reaction development during storage both in protein glucose model system and low lactose UHT milk," Amino Acids, vol. 46, no. 2, pp. 279-288, 2014.

[19] O. Z. De Vita, Encyclopedia of Pasta, vol. 26, University of California Press, 2009.

[20] P. della Repubblica, "Legge No 580 of 4th July 1967 on Disciplina per la lavorazione e commercio dei cereali, degli sfarinati, del pane e delle paste alimentari," Gazzetta Ufficiale, no. 189, 1967.

[21] J. E. Dexter, R. R. Matsuo, and B. C. Morgan, "High temperature drying: effect on spaghetti properties," Journal of Food Science, vol. 46, no. 6, pp. 1741-1746, 1981.

[22] A. Baiano, A. Conte, and M. A. del Nobile, "Influence of drying temperature on the spaghetti cooking quality," Journal of Food Engineering, vol. 76, no. 3, pp. 341-347, 2006.

[23] G. A. Reineccius, "The influence of Maillard reactions on the sensory properties of foods," in The Maillard Reaction in Food Processing, Human Nutrition and Physiology, P. A. Finot, H. U. Aeschbacher, R. F. Hurrel, and R. Liardon, Eds., pp. 157-170, Birkhäuser, Basel, Switzerland, 1990.

[24] R. Beleggia, C. Platani, R. Papa et al., "Metabolomics and food processing: from semolina to pasta," Journal of Agricultural and Food Chemistry, vol. 59, no. 17, pp. 9366-9377, 2011.

[25] J. L. García-Baños, N. Corzo, M. L. Sanz, and A. Olano, "Maltulose and furosine as indicators of quality of pasta products," Food Chemistry, vol. 88, no. 1, pp. 35-38, 2004.

[26] K. I. Skog, M. A. E. Johansson, and M. I. Jägerstad, "Carcinogenic heterocyclic amines in model systems and cooked foods: a review on formation, occurrence and intake," Food and Chemical Toxicology, vol. 36, no. 9-10, pp. 879-896, 1998.

[27] R. Sinha, M. G. Knize, C. P. Salmon et al., "Heterocyclic amine content of pork products cooked by different methods and to varying degrees of doneness," Food and Chemical Toxicology, vol. 36, no. 4, pp. 289-297, 1998.

[28] J. Lin, J. Wang, H. B. Grossman, M. Chen, C. P. Dinney, and $\mathrm{X}$. Wu, "Red meat and heterocyclic amine intake, metabolic pathway genes, and bladder cancer risk," Cancer Research, vol. 70, no. 8, supplement, p. 2825, 2010.

[29] A. J. Cross, L. M. Ferrucci, A. Risch et al., "A large prospective study of meat consumption and colorectal cancer risk: an investigation of potential mechanisms underlying this association," Cancer Research, vol. 70, no. 6, pp. 2406-2414, 2010.
[30] K. Augustsson, K. Skog, M. Jägerstad, P. W. Dickman, and G. Steineck, "Dietary heterocyclic amines and cancer of the colon, rectum, bladder, and kidney: a population-based study," The Lancet, vol. 353, no. 9154, pp. 703-707, 1999.

[31] N. J. Ollberding, L. R. Wilkens, B. E. Henderson, L. N. Kolonel, and L. le Marchand, "Meat consumption, heterocyclic amines and colorectal cancer risk: the Multiethnic Cohort Study," International Journal of Cancer, vol. 131, no. 7, pp. E1125-E1133, 2012.

[32] A. Sander, J. Linseisen, and S. Rohrmann, "Intake of heterocyclic aromatic amines and the risk of prostate cancer in the EPIC-Heidelberg cohort," Cancer Causes \& Control, vol. 22, no. 1, pp. 109-114, 2011.

[33] B. G. Abdulkarim and J. S. Smith, "Heterocyclic amines in fresh and processed meat products," Journal of Agricultural and Food Chemistry, vol. 46, no. 11, pp. 4680-4687, 1998.

[34] M. G. Knize and J. S. Felton, "Formation and human risk of carcinogenic heterocyclic amines formed from natural precursors in meat," Nutrition Reviews, vol. 63, no. 5, pp. 158-165, 2005.

[35] K. W. Cheng, F. Chen, and M. Wang, "Heterocyclic amines: chemistry and health," Molecular Nutrition \& Food Research, vol. 50, no. 12, pp. 1150-1170, 2006.

[36] D. Mottram, "Some aspects of the chemistry of meat flavour," in Flavor of Meat and Meat Products, pp. 210-230, Springer, Berlin, Germany, 1994.

[37] D. S. Mottram, "Flavour formation in meat and meat products: a review," Food Chemistry, vol. 62, no. 4, pp. 415-424, 1998.

[38] J. Felton and M. Knize, "Heterocyclic-amine mutagens/carcinogens in foods," in Chemical Carcinogenesis and Mutagenesis I, pp. 471-502, Springer, Berlin, Germany, 1990.

[39] G. Z. Liao, G. Y. Wang, Y. J. Zhang, X. L. Xu, and G. H. Zhou, "Formation of heterocyclic amines during cooking of duck meat," Food Additives and Contaminants Part A: Chemistry, Analysis, Control, Exposure and Risk Assessment, vol. 29, no. 11, pp. 1668-1678, 2012.

[40] G. Z. Liao, G. Y. Wang, X. L. Xu, and G. H. Zhou, "Effect of cooking methods on the formation of heterocyclic aromatic amines in chicken and duck breast," Meat Science, vol. 85, no. 1, pp. 149-154, 2010.

[41] R. Sinha, N. Rothman, C. P. Salmon et al., "Heterocyclic amine content in beef cooked by different methods to varying degrees of doneness and gravy made from meat drippings," Food and Chemical Toxicology, vol. 36, no. 4, pp. 279-287, 1998.

[42] K. Puangsombat, P. Gadgil, T. A. Houser, M. C. Hunt, and J. S. Smith, "Heterocyclic amine content in commercial ready to eat meat products," Meat Science, vol. 88, no. 2, pp. 227-233, 2011.

[43] M. G. Knize, R. Sinha, E. D. Brown et al., "Heterocyclic amine content in restaurant-cooked hamburgers, steaks, ribs, and chicken," Journal of Agricultural and Food Chemistry, vol. 46, no. 11, pp. 4648-4651, 1998.

[44] L. M. Tikkanen, K. J. Latva-Kala, and R.-L. Heiniö, "Effect of commercial marinades on the mutagenic activity, sensory quality and amount of heterocyclic amines in chicken grilled under different conditions," Food and Chemical Toxicology, vol. 34, no. 8, pp. 725-730, 1996.

[45] A. Crozier, H. Ashihara, and F. Tomás-Barbéran, Teas, Cocoa and Coffee: Plant Secondary Metabolites and Health, John Wiley \& Sons, New York, NY, USA, 2011.

[46] M. S. Butt and M. T. Sultan, "Coffee and its consumption: benefits and risks," Critical Reviews in Food Science and Nutrition, vol. 51, no. 4, pp. 363-373, 2011. 
[47] H.-D. Belitz, W. Grosch, and P. Schieberle, "Coffee, tea, cocoa," Food Chemistry, pp. 938-970, 2009.

[48] R. Tressl, G. T. Wondrak, L.-A. Garbe, R.-P. Krüger, and D. Rewicki, "Pentoses and hexoses as sources of new melanoidinlike Maillard polymers," Journal of Agricultural and Food Chemistry, vol. 46, no. 5, pp. 1765-1776, 1998.

[49] M. Daglia, R. Tarsi, A. Papetti et al., "Antiadhesive effect of green and roasted coffee on Streptococcus mutans' adhesive properties on saliva-coated hydroxyapatite beads," Journal of Agricultural and Food Chemistry, vol. 50, no. 5, pp. 1225-1229, 2002.

[50] M. D. del Castillo, N. Corzo, and A. Olano, "Early stages of Maillard reaction in dehydrated orange juice," Journal of Agricultural and Food Chemistry, vol. 47, no. 10, pp. 4388-4390, 1999.

[51] M. L. Sanz, M. Dolores del Castillo, N. Corzo, and A. Olano, "Presence of 2-furoylmethyl derivatives in hydrolysates of processed tomato products," Journal of Agricultural and Food Chemistry, vol. 48, no. 2, pp. 468-471, 2000.

[52] A. Wellner, C. Huettl, and T. Henle, "Formation of Maillard reaction products during heat treatment of carrots," Journal of Agricultural and Food Chemistry, vol. 59, no. 14, pp. 7992-7998, 2011.

[53] V. Dueik and P. Bouchon, "Vacuum frying as a route to produce novel snacks with desired quality attributes according to new health trends," Journal of Food Science, vol. 76, no. 2, pp. E188E195, 2011.

[54] M. Anese, L. Manzocco, M. C. Nicoli, and C. R. Lerici, "Antioxidant properties of tomato juice as affected by heating," Journal of the Science of Food and Agriculture, vol. 79, no. 5, pp. 750-754, 1999.

[55] T. Hofmann, W. Bors, and K. Stettmaier, "Studies on radical intermediates in the early stage of the nonenzymatic browning reaction of carbohydrates and amino acids," Journal of Agricultural and Food Chemistry, vol. 47, no. 2, pp. 379-390, 1999.

[56] L. R. Fukumoto and G. Mazza, "Assessing antioxidant and prooxidant activities of phenolic compounds," Journal of Agricultural and Food Chemistry, vol. 48, no. 8, pp. 3597-3604, 2000.

[57] C. Billaud, C. Maraschin, Y.-N. Chow, S. Chériot, M.-N. PeyratMaillard, and J. Nicolas, "Maillard reaction products as "natural antibrowning" agents in fruit and vegetable technology," Molecular Nutrition and Food Research, vol. 49, no. 7, pp. 656-662, 2005.

[58] P. Gruber, S. Vieths, A. Wangorsch, J. Nerkamp, and T. Hofmann, "Maillard reaction and enzymatic browning affect the allergenicity of Pru av 1, the major allergen from cherry (Prunus avium)," Journal of Agricultural and Food Chemistry, vol. 52, no. 12, pp. 4002-4007, 2004.

[59] A. Pihlanto-Leppälä, "Bioactive peptides derived from bovine whey proteins: opioid and ace-inhibitory peptides," Trends in Food Science and Technology, vol. 11, no. 9-10, pp. 347-356, 2000.

[60] J. A. Rufián-Henares and F. J. Morales, "Functional properties of melanoidins: in vitro antioxidant, antimicrobial and antihypertensive activities," Food Research International, vol. 40, no. 8 , pp. 995-1002, 2007.

[61] X. Hong, J. Meng, and R.-R. Lu, "Improvement of ACE inhibitory activity of casein hydrolysate by Maillard reaction with xylose," Journal of the Science of Food and Agriculture, vol. 95, no. 1, pp. 66-71, 2015.

[62] K. S. Kang, K. I. Su-Nam, J. Ham, W. Lee, N. Yamabe, and J. H. Lee, "Composition for preventing, improving, or treating renal disease including maillard browning reaction products of panax species plant extract," Google Patents, 2013.
[63] V. T. Trang, V. H. Son, L. X. Thanh et al., "Functional properties of maillard reaction products in food: antimicrobial activity of aminoreductone against pathogenic bacteria," Food Science and Technology Research, vol. 19, no. 5, pp. 833-841, 2013.

[64] A. Tauer, S. Elss, M. Frischmann, P. Tellez, and M. Pischetsrieder, "Influence of thermally processed carbohydrate/amino acid mixtures on the fermentation by Saccharomyces cerevisiae," Journal of Agricultural and Food Chemistry, vol. 52, no. 7, pp. 2042-2046, 2004.

[65] Cancer IAfRo, IARC Monographs on the Evaluation of the Carcinogenic Risk of Chemicals to Humans. Overall Evaluations of Carcinogenicity: An Updating of IARC Monographs, vol. 1-42, World Health Organization, 1987.

[66] D. S. Mottram, B. L. Wedzicha, and A. T. Dodson, "Food chemistry: acrylamide is formed in the Maillard reaction," Nature, vol. 419, no. 6906, pp. 448-449, 2002.

[67] R. H. Stadler, I. Blank, N. Varga et al., "Food chemistry: acrylamide from Maillard reaction products," Nature, vol. 419, no. 6906, pp. 449-450, 2002.

[68] E. Tareke, P. Rydberg, P. Karlsson, S. Eriksson, and M. Törnqvist, "Analysis of acrylamide, a carcinogen formed in heated foodstuffs," Journal of Agricultural and Food Chemistry, vol. 50, no. 17, pp. 4998-5006, 2002.

[69] E. Capuano, A. Ferrigno, I. Acampa, L. Ait-Ameur, and V. Fogliano, "Characterization of the Maillard reaction in bread crisps," European Food Research and Technology, vol. 228, no. 2, pp. 311-319, 2008.

[70] D. V. Zyzak, R. A. Sanders, M. Stojanovic et al., "Acrylamide formation mechanism in heated foods," Journal of Agricultural and Food Chemistry, vol. 51, no. 16, pp. 4782-4787, 2003.

[71] M. T. Masatcioglu, V. Gokmen, P. K. W. Ng, and H. Koksel, "Effects of formulation, extrusion cooking conditions, and $\mathrm{CO}_{2}$ injection on the formation of acrylamide in corn extrudates," Journal of the Science of Food and Agriculture, vol. 94, no. 12, pp. 2562-2568, 2014. 

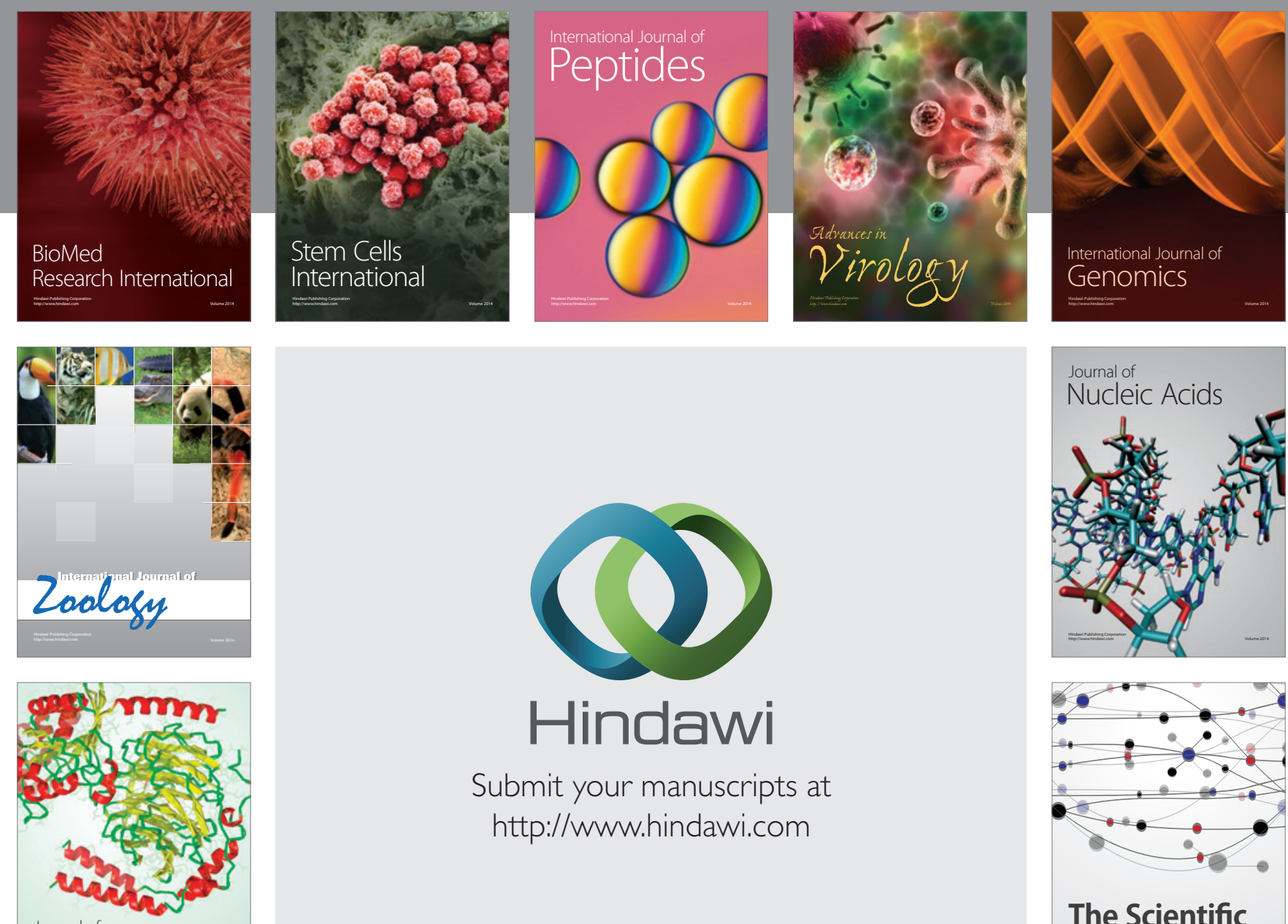

Submit your manuscripts at

http://www.hindawi.com

Journal of
Signal Transduction
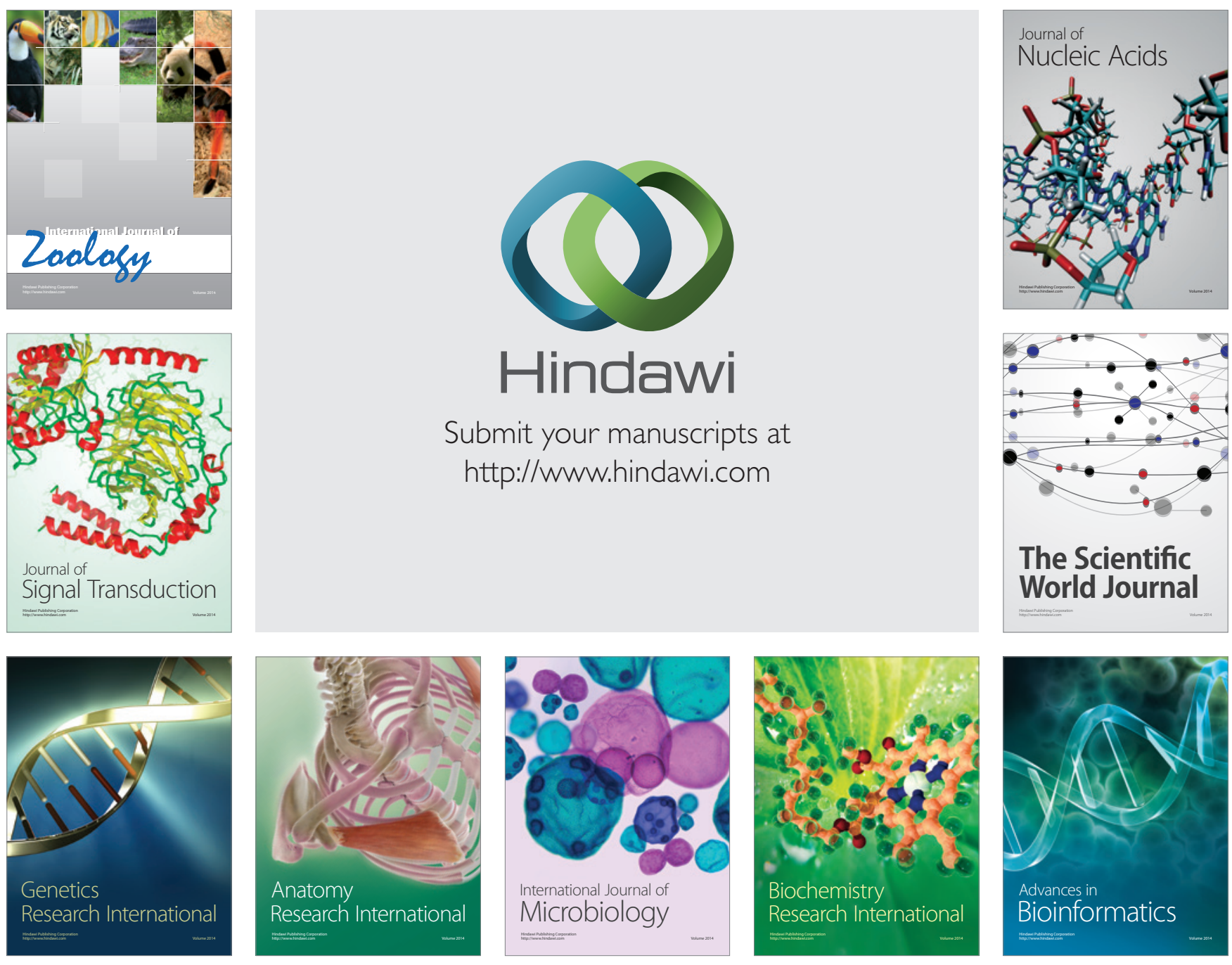

The Scientific World Journal
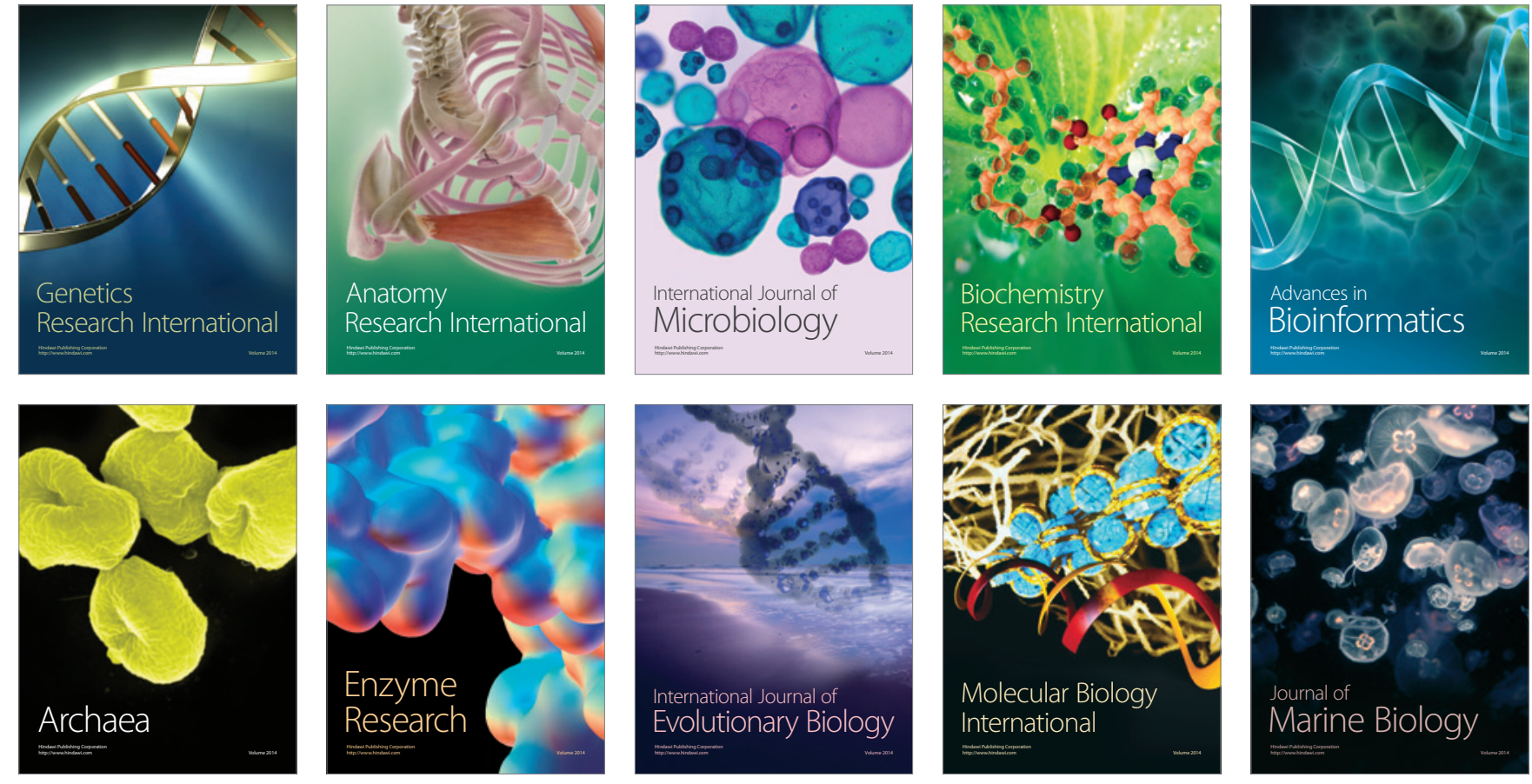